\title{
High cases of submicroscopic Plasmodium falciparum infections in a suburban population of Lagos, Nigeria
}

\author{
Florence A. Umunnakwe1, Emmanuel T. Idowu' , Olusola Ajibaye², Blessed Etoketim³ , Samuel Akindele², \\ Aminat O. Shokunbi', Olubunmi A. Otubanjo', Gordon A. Awandare', Alfred Amambua-Ngwa ${ }^{3}$ \\ and Kolapo M. Oyebola $a^{1,2,3,4^{*}}$ (D)
}

\begin{abstract}
Background: Asymptomatic malaria parasites are significant sources of infections for onward malaria transmission. Conventional tools for malaria diagnosis such as microscopy and rapid diagnostic test kits (RDT) have relatively low sensitivity, hence the need for alternative tools for active screening of such low-density infections.

Methods: This study tested var acidic terminal sequence-based (varATS) quantitative polymerase chain reaction (qPCR) for screening asymptomatic Plasmodium falciparum infections among dwellers of a sub-urban community in Lagos, Nigeria. Clinically healthy participants were screened for malaria using microscopy, RDT and varATS qPCR techniques. Participants were stratified into three age groups: 1-5, 6-14 and $>14$ years old.

Results: Of the 316 participants screened for asymptomatic malaria infection, 78 (24.68\%) were positive by microscopy, 99 (31.33\%) were positive by RDT and 112 (35.44\%) by varATS qPCR. Participants aged $6-14$ years had the highest prevalence of asymptomatic malaria, with geometric means of $\sim 116$ parasites $/ \mu \mathrm{L}$ and $\sim 6689$ parasites $/ \mu \mathrm{L}$ as detected by microscopy and varATS, respectively.

Conclusion: This study has revealed high prevalence of asymptomatic malaria in the study population, with varATS detecting additional sub-microscopic infections. The highest concentration of asymptomatic malaria was observed among school-age children between 6 and 14 years old. A large-scale screening to identify other potential hotspots of asymptomatic parasites in the country is recommended.
\end{abstract}

Keywords: Asymptomatic malaria, Rapid diagnostic test, Microscopy, varATS, Plasmodium falciparum, Nigeria, qPCR

\section{Background}

Malaria remains a major cause of morbidity and mortality in sub-Saharan Africa. The prevalence of malaria has remained static in recent years unlike the success recorded in early 2000s [1]. Consequently, there is a need for localized and country-specific interventions,

\footnotetext{
*Correspondence: oyebolakolapo@yahoo.com; kolapo.oyebola@nih.gov 1 Parasitology and Bioinformatics Unit, Department of Zoology, Faculty of Science, University of Lagos, Akoka, Lagos, Nigeria

Full list of author information is available at the end of the article
}

particularly prompt diagnosis of infections and treatment to control transmission. Nigeria currently contributes approximately one-third of the global burden of malaria [1]. Control efforts in the country rely principally on passive diagnosis at health facilities by clinical examination or by parasitological confirmation [2]. However, the recent transition in malaria research priorities from control to elimination emphasizes the need to monitor both clinical and asymptomatic infections [3]. While case detection of clinical malaria has been largely successful $[4,5]$, confirmation of asymptomatic infections, which

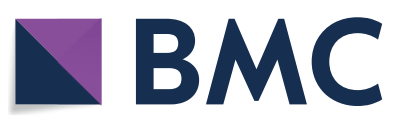

(c) The Author(s) 2019. This article is licensed under a Creative Commons Attribution 4.0 International License, which permits use, sharing, adaptation, distribution and reproduction in any medium or format, as long as you give appropriate credit to the original author(s) and the source, provide a link to the Creative Commons licence, and indicate if changes were made. The images or other third party material in this article are included in the article's Creative Commons licence, unless indicated otherwise in a credit line to the material. If material is not included in the article's Creative Commons licence and your intended use is not permitted by statutory regulation or exceeds the permitted use, you will need to obtain permission directly from the copyright holder. To view a copy of this licence, visit http://creativeco mmons.org/licenses/by/4.0/. The Creative Commons Public Domain Dedication waiver (http://creativecommons.org/publicdomain/ zero/1.0/) applies to the data made available in this article, unless otherwise stated in a credit line to the data. 
are usually below microscopy-detectable levels and are rarely treated, remains a major challenge [6]. As a major source of parasites for local mosquito vectors, undetected asymptomatic infections contribute to the persistence of malaria transmission [7]. These asymptomatic parasites have also been linked with chronic anaemia and co-infections with invasive bacteria [8] .

Although there have been some success stories of malaria reduction following rapid diagnostic test kits (RDTs) and microscopy-based diagnosis [9, 10], both tools have limited sensitivity in detecting sub-clinical infections $[11,12]$. It is believed that better malaria control or elimination outcomes would be achieved if lowdensity parasitaemias were detected [13, 14]. Moreover, the introduction of conventional polymerase chain reaction (PCR) tools in estimating the burden of asymptomatic malaria has achieved only little improvement at a threshold of $0.05-10$ parasites $/ \mu \mathrm{L}[15,16]$. Since parasitaemia of $0.05 / \mu \mathrm{L}$ of blood corresponds to as high as approximately 100,000 parasites in the body [17], such undetectable ultra-low infections may sustain malaria transmission.

A relatively recent technique for the ultra-sensitive detection of low parasitaemia has so far yielded promising outcomes [18]. This procedure involves the amplification of the var gene family present in the subtelomere of the parasite. Each parasite isolate comprises about 50-150 var genes, which possess acidic terminal sequences (ATS) with well-conserved domains [18]. PCR targeting varATS of the parasite has a high sensitivity with a limit of detection of 0.03 parasites/ $\mu \mathrm{L}$ blood [18]. While microscopy, RDTs and conventional PCR tools have been extensively evaluated for asymptomatic malaria diagnosis in Nigeria [19-22], there are no data on the performance and effectiveness of varATS quantitative PCR (varATS qPCR) for diagnosing asymptomatic Plasmodium falciparum infections in the country. This study evaluated the effectiveness of varATS qPCR against conventional microscopy and RDTs for the assessment of asymptomatic $P$. falciparum carriage among sub-urban settlers in Lagos, Nigeria.

\section{Methods}

\section{Study design and sample collection}

A cross-sectional, community-based study was carried out in July 2018 to screen residents of Bayeku for asymptomatic malaria. Bayeku is a rural community in Ikorodu Local Government, an outskirt of Lagos, Nigeria. Malaria is meso-endemic in Lagos, with peak transmission during the rainy season between April and September of every year $[23,24]$. The geographical coordinates of Bayeku are $6^{\circ} 35^{\prime} 60^{\prime \prime} \mathrm{N}$ and $3^{\circ} 30^{\prime} 0^{\prime \prime} \mathrm{E}$ (Fig. 1). Following mobilization and advocacy by community representatives, screening was conducted at the community town hall within the palace of the traditional ruler. Blood samples were collected from a finger prick for microscopy and RDT performance. For molecular analysis, blood was spotted on filter paper (Whatmann 3MM General Electric Healthcare Co., UK). The blood spots were left on the bench to dry after which they were put in individual ziplock plastic bags containing desiccant and stored at room temperature $\left(<30{ }^{\circ} \mathrm{C}\right)$. Participants were visibly healthy individuals who had been resident in the community for more than 2 years and were without a history of fever or symptoms suggestive of malaria in the preceding 2 days. Exclusion criteria in this investigation were nonconsenting individuals, patients who received anti-malarial therapy in the preceding 4 weeks before sampling, pregnant women as well as children under 1 year old, to preclude the influence of maternally inherited immunity [25]. Asymptomatic (or sub-clinical) malaria was defined as the presence of malaria parasites in a patient who showed no clinical evidence of infection at the time of diagnosis [8]. Participants were considered asymptomatic when the body temperature was $<37.5^{\circ} \mathrm{C}$ at the time of blood collection and the participant reported no fever within the previous 2 days.

\section{Rapid diagnostic testing (RDT) and microscopy}

Blood samples were tested for malaria parasites using CareStart $^{\mathrm{TM}}$ Malaria HRP2 (P. falciparum; CAT NO: G0141, Access Bio Inc., USA). Thick and thin blood films were prepared on a glass slide for parasite identification and speciation using Giemsa technique. The slides were stained and viewed using $100 \times$ oil immersion objective lens of a compound microscope. At least 100 high power fields were examined before a thick smear was reported as negative. For positive slides, parasite species and stages were assessed and parasitaemia (parasite density) was determined by counting only the asexual stages against 300 white blood cells (WBC) and then multiplying by 25 , assuming the mean total WBC count of individuals is 7500 cells $/ \mu \mathrm{L}$ of blood [17]. Slides were blindly read by two independent level 1 microscopists. Positive/negative cases were called only after confirmation by both microscopists. Microscopybased estimates of parasite density were calculated as the average of the values that were within the margin of between-reader difference. Two readings were considered discrepant if their difference was outside the 95\% range of the limits of agreement of previous paired readings [26]. The level of parasitaemia was recorded as low $(<1000$ parasites $/ \mu \mathrm{L}$ of blood), moderate $(1000-$ 9999 parasites $/ \mu \mathrm{L}$ of blood), and severe $(\geq 10,000$ parasites/ $\mu \mathrm{L}$ of blood) [27]. 


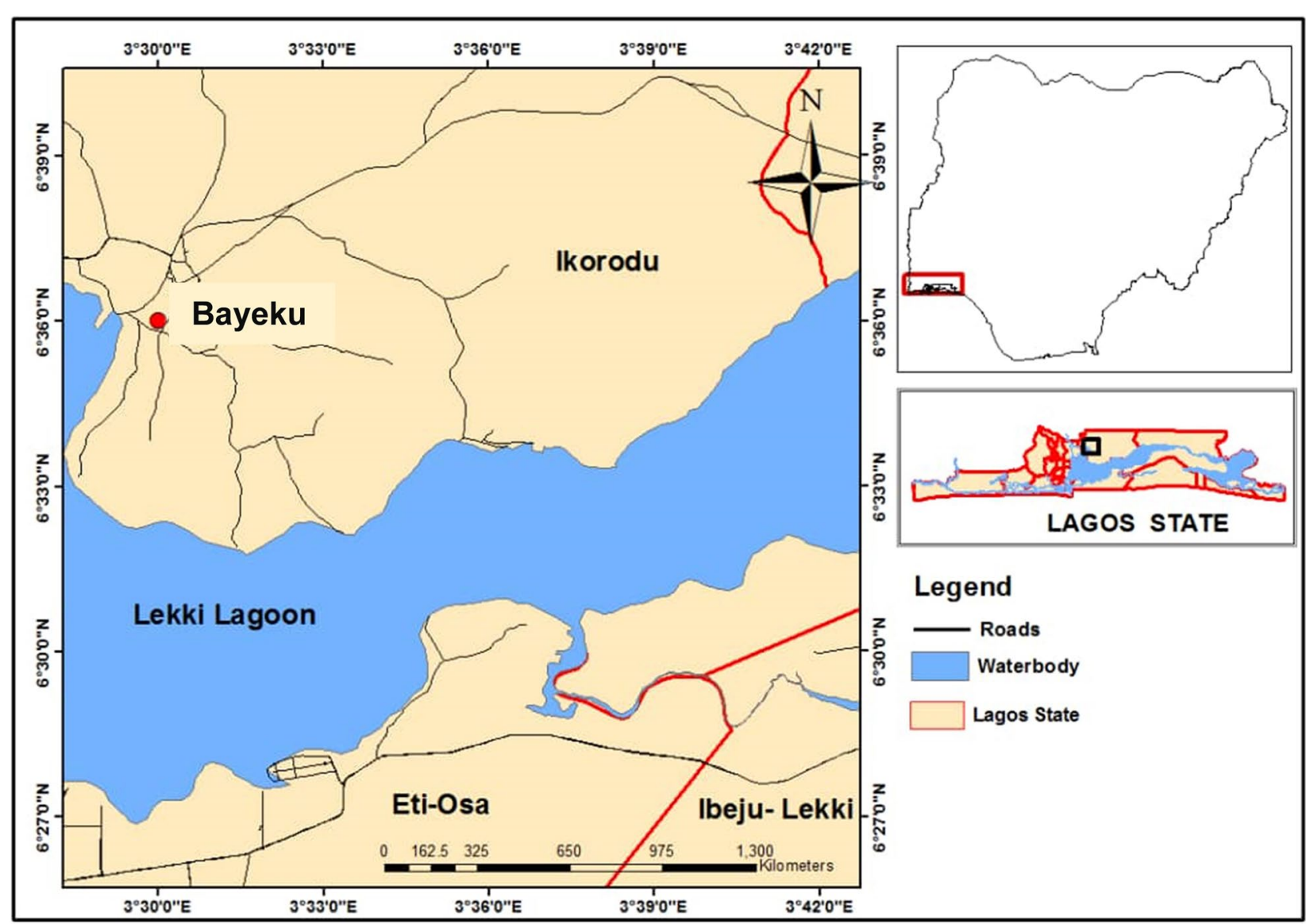

Fig. 1 Map of Nigeria (inset) showing the location of study area

\section{varATS qPCR diagnosis of asymptomatic malaria}

Plasmodium falciparum DNA was extracted from dried blood spots using the QiaAmp DNA minikit (Qiagen, Germany). The var gene acidic terminal sequence (varATS) quantitative PCR was used to detect multi-copy genomic sequences of low-density infections [18]. The primer/probe sequences and the cycling conditions are described in Table 1 . Briefly, $1 \mu \mathrm{L}$ of PCR water, $10 \mu \mathrm{L}$ of $2 \times$ Taqman Universal PCR Mastermix (Applied Biosystems, New Jersey, USA), $1.6 \mu \mathrm{L}$ of $10 \mathrm{uM}$ forward and reverse primers, $0.8 \mu \mathrm{L}$ of $10 \mu \mathrm{M}$ probe and $5 \mu \mathrm{L}$ of parasite DNA were vortexed and run on CFX 96 Touch $^{\mathrm{TM}}$ Real-Time System (Bio-Rad Laboratories, CA, USA). The turnaround time was approximately $3 \mathrm{~h}$. The starting quantity (SQ) values of the parasite samples were estimated against laboratory grown $P$. falciparum 3D7 standard control (with medonic read of $3.74 \times 106$ erythrocytes $/ \mu \mathrm{L}$ and thin film parasitaemia of 1197 parasites $/ \mu \mathrm{L}$ of blood). The serial dilution procedure is described in Additional file 3: Sheet S1.

\section{Statistical analysis}

Participants were stratified into three age categories: $1-5$ years, $6-14$ years and $>14$ years. Data from this study were coded, entered and analysed in GraphPad Prism 8. The difference in parasite densities between age groups was analysed using Chi-square $\left(\mathrm{X}^{2}\right)$ test and P-value $<0.05$ was considered statistically significant. Student's t-test was used for comparison of means. Kappa (K) coefficient was used to test the measure of agreement between RDT and varATS as well as microscopy vs varATS. K values $<0.20,0.21-0.40,0.41-0.60,0.61-0.80$, and $0.8-$ 1.0 depicted poor, fair, moderate, good, and very good strengths of agreement, respectively [28]. 
Table 1 Primer sequences and qPCR conditions for varATS assay

\begin{tabular}{ll}
\hline Oligonucleotide sequences & \\
Primer-fw $\left(5^{\prime}-3^{\prime}\right)$ & CCCATACACAACCAATTGGA \\
Primer-rev $\left(5^{\prime}-3^{\prime}\right)$ & TTCGCACATATCTCTATGTCTATCT \\
Probe $\left(5^{\prime}-3^{\prime}\right)$ & 6-FAM-TTTTCCATAAATGGT-NFQ-MGB \\
qPCR reaction conditions (final concentration in qPCR mix) & 20 \\
Total volume $(\mu \mathrm{L})$ & 5 \\
DNA volume $(\mu \mathrm{L})$ & $1 \times$ \\
TaqMan ${ }^{\circledR}$ Gene Expression Mastermix & $800 \mathrm{nM}$ \\
Primer (each) & $400 \mathrm{nM}$ \\
Probe & \\
qPCR cycling conditions & 2 min-50 ${ }^{\circ} \mathrm{C}$ \\
Pre-incubation & 10 min-95 ${ }^{\circ} \mathrm{C}$ \\
Initial denaturation & 15 s-95 ${ }^{\circ} \mathrm{C}$ \\
Denaturation & 1 min-55 ${ }^{\circ} \mathrm{C}$ \\
Annealing and elongation & 45 \\
Number of cycles & gDNA of parasite dilution row \\
Standard material for quantification & Real-Time PCR System (Applied Biosystems) \\
Platform &
\end{tabular}

Table 2 Demographic characteristics of participants

\begin{tabular}{lll}
\hline Variable & Attribute & Number (\%) \\
\hline Age group (years) & $1-5$ & $67(21.2)$ \\
& $6-14$ & $96(30.4)$ \\
Gender & $>14$ & $153(48.4)$ \\
& Female & $201(63.7)$ \\
Total & Male & $115(36.3)$ \\
\hline
\end{tabular}

\section{Results}

A total of 316 asymptomatic participants were screened for P. falciparum out of which 125 (39.56\%) were positive by at least one of microscopy, RDT and varATS diagnostics. The demographic profile of participants is summarized in Table 2. Briefly, the ages of the participants ranged between 1 and 100 years with mean age $=23.15$ years. Individuals 15 years and above formed the majority of participants with 153 (48.4\%), this was followed by age group $6-14$ years and $1-5$ years with 96 (30.4\%) and 67 (21.2\%), respectively (Table 2 ).

Microscopy/RDT/varATS PCR counts were used to ascertain the prevalence of asymptomatic malaria in the study population. Prevalence of asymptomatic infections was $78(24.68 \%)$ and 99 (31.33\%) for microscopy and RDT, respectively, while varATS qPCR detected additional $10 \%$ sub-microscopic infections in the population 112 (35.44\%). The geometric mean parasite density by varATS was higher in male participants (5409.86/ $\mu \mathrm{L}$ ) (Additional file 2: Tables S1, S2). When stratified by

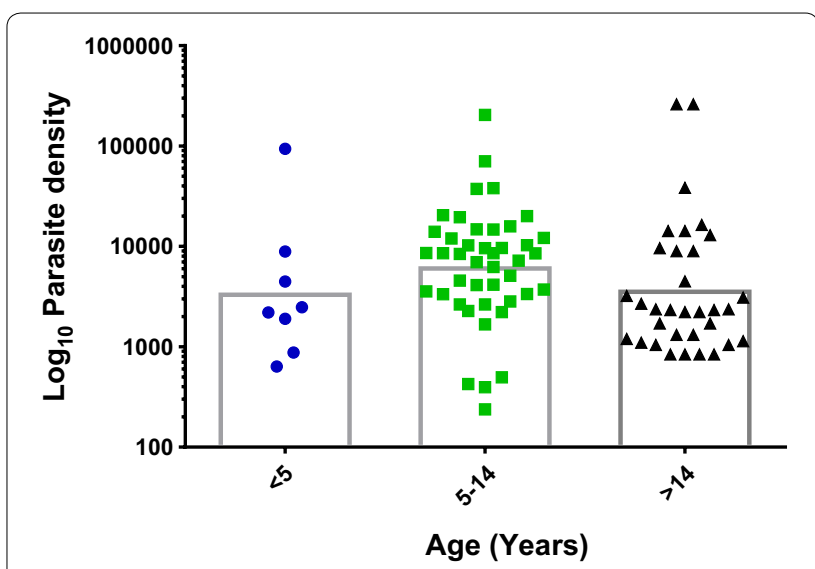

Fig. 2 Age groups of participants and parasite density by varATS (error bars showing geomean with 95\% Cl)

age groups (1-5, 6-14 and $>14$ years), parasite densities were low in children younger than $5(3566.28 / \mu \mathrm{L})$. Participants aged 6-14 years had the highest cases and density of asymptomatic parasitaemia using varATS qPCR with geometric mean of $6688.91 / \mu \mathrm{L}$ (Additional file 2: Table S3; Fig. 2).

The proportion of positive cases detected by varATS, microscopy, RDT, RDT/microscopy, varATS/microscopy, varATS/RDT, and varATS/RDT/microscopy were compared. All $P$. falciparum-positive cases detected by microscopy were also varATS positive. However, 8 positive diagnoses by RDT were negative by both microscopy and varATS (Additional file 1: Sheet S1). In addition, 


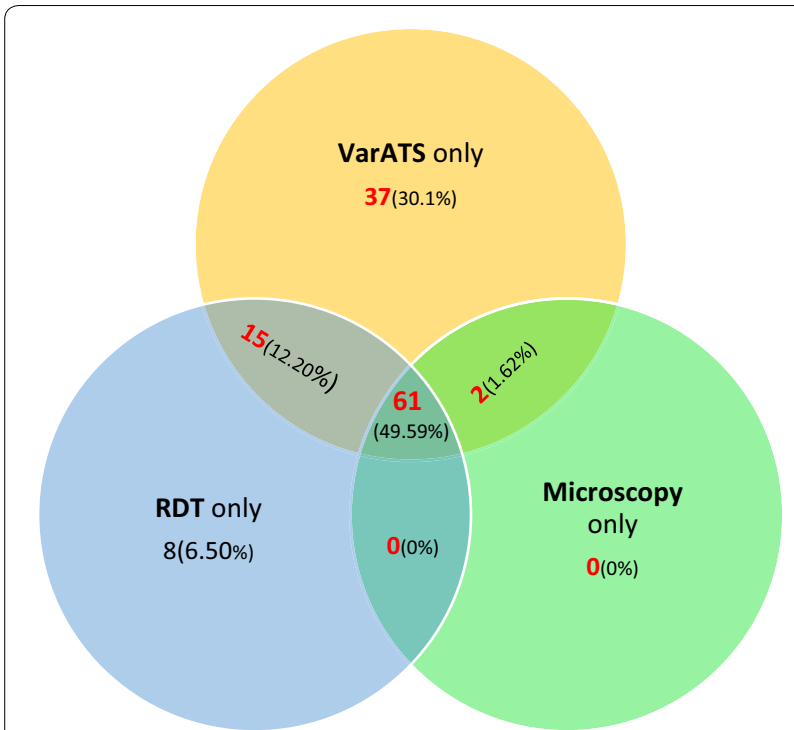

Fig. 3 Detection of asymptomatic malaria by RDT, microscopy and varATS qPCR

37 (30.1\%) of varATS-positive individuals were neither detected by microscopy nor RDT (Fig. 3). The measure of agreement of RDT versus varATS results (Kappa $=0.74)$ was higher than microscopy versus varATS (Kappa =0.67). When the sensitivity and specificity of RDT and microscopy were benchmarked against varATS (Additional file 2: Tables S4, S5), higher sensitivity of RDT (73.9\%) than microscopy $(63.0 \%)$ was observed. Microscopy (99.5\%) was, however, found to be slightly more specific for asymptomatic infections than RDT (97\%). VarATS parasite densities below $174.84 / \mu \mathrm{L}$ were undetectable by microscopy. However, the threshold was slightly lower for RDT, which consistently detected parasitaemia beyond 110.38/uL (Additional file 3: Sheet S1).

Furthermore, there was a significant difference in parasite carriage between different age groups (P-value $<0.001$; Additional file 2: Table S6). Microscopy and RDT results showed that participants who were positive for asymptomatic malaria were significantly younger than negative individuals (Additional file 2: Tables S7, S8; Table 3). In the varATS group, however, there was no major difference across age groups or gender (Additional file 2: Table S9; Fig. 4).

\section{Discussion}

Sub-clinical malaria has been associated with mild anaemia [29] and adverse effects in pregnant women [30]. Even more dire is the public health consequence of lowdensity infections [31]. Accurate prevalence estimates are important for systematic identification and treatment of individuals with asymptomatic falciparum malaria, as

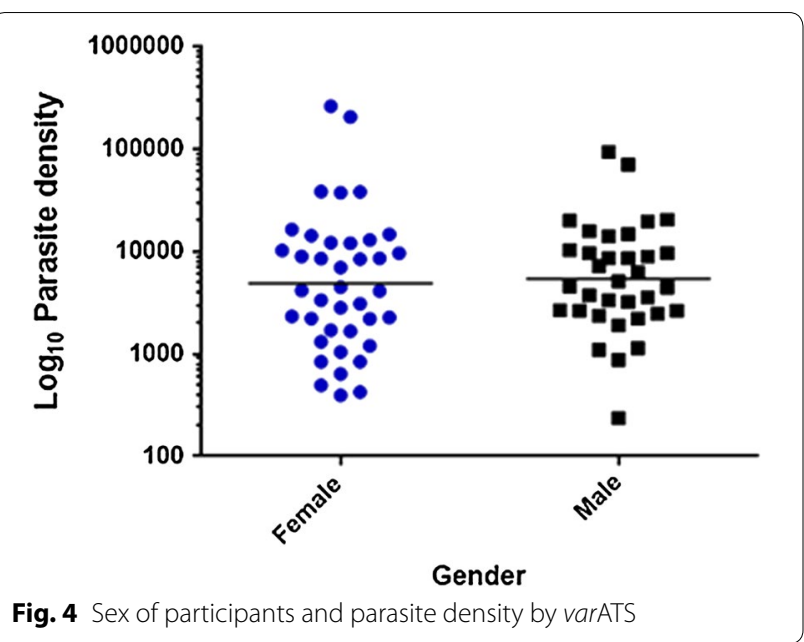

part of an intervention strategy, to reduce transmission of the disease. In this study, varATS was used to detect asymptomatic infections among sub-urban settlers in Lagos, Nigeria. The prevalence of asymptomatic malaria reported was high at $35.4 \%$. Although microscopy and varATS diagnosis shared a fairly modest level of agreement, varATS analysis showed that sub-microscopic infections were present in an additional $10 \%$ of the population. The lower rate of microscopic detection observed here compared to varATS is consistent with a previous investigation [32].

Analysis of the relationship between RDT and microscopy sensitivity revealed higher numbers of asymptomatic infections detected by RDT relative to microscopy. This challenges existing knowledge, which implies less sensitivity of RDT than microscopy [33] even though this study did not foreclose the possibility of false positive diagnosis by RDT as 8 RDT-positive diagnoses, that were neither microscopy nor varATS positive, were reported. Nonetheless, the RDT detection limit (110.38/ $\mu \mathrm{L})$, benchmarked against varATS in this study, is consistent with the assertion that the detection limit of RDTs is typically around 100 parasites/ $\mu \mathrm{L}$ [33]. Meanwhile, the high proportion of sub-microscopic infections, as reported here, provides evidence of ongoing transmission of malaria. This may suggest that the integrated control approach adopted by the Lagos State Malaria Research, Technical and Advisory Committee (LASMARTAC) has not effectively reduced malaria transmission in the community. As asymptomatic infections are enough to restart transmission [34, 35], an intensified approach that will incorporate molecular diagnostics to target, treat and follow up sub-microscopic infections is advocated.

Microscopy and RDT analyses showed that participants who were positive for asymptomatic malaria were 
significantly younger than those who tested negative. In the varATS group, however, there was no major difference across age groups. This provides additional evidence of the effectiveness of varATS to detect malaria parasites across all age groups. Older individuals are expected to acquire immunity from several episodes of malaria during the early part of their lives [36, 37], hence a higher prevalence of sub-clinical infections should be expected with increasing age. However, the report from this study did not conform to this convention. Specifically, a higher frequency of asymptomatic infections was observed in the 6-14 years group (school-age children) than in individuals in older adults. This corroborates previous findings that revealed high prevalence of asymptomatic parasitaemia in individuals aged 5 to 15 years [38-40]. A plausible interpretation of this finding is that schoolage children are possibly more exposed to infection, and they may build up immunity against clinical malaria in the process. Walldorf et al. [40] reported that school-age children sleep under nets less often than any other age group. This lack of utilization of preventive measures and engagement in outdoor activities may partly explain increased prevalence in this group of children. National malaria control programmes should pay more attention to malaria in school-age children. Integration of malaria intervention strategies with other school-based programmes is recommended.

Meanwhile, there could be other factors contributing to the prevalence of sub-microscopic infections that were not described in this study. Treatment inefficacy, for instance, may influence residual carriage of infections [41, 42]. Oyebola et al. [43] reported that artemisinin-based treatment of clinical infections led to the persistence of sub-microscopic parasitaemia. Detailed longitudinal data from drug therapeutic efficacy trials will be required to clarify this observation. Another limitation of this study is that the varATS PCR technique has only been developed for P. falciparum diagnosis [18]. Therefore, there is a high chance of non-detection of other malaria species. Moreover, it is important to consider cross-sectional surveillance of ultra-low-density infections for daily fluctuations in parasite density and virulence in subsequent studies. A longitudinal study that effectively measures parasite kinetics, gametocyte production and transmission potential of low-density infections will be useful for malaria control in Nigeria. If provisions are made to subsidize operational costs of varATS, the deployment of the molecular tool in field diagnosis will facilitate malaria elimination.
Table 3 Comparison of mean age of study participants

\begin{tabular}{llll}
\hline & Mean age \pm SD (years) & F & P-value \\
\hline RDT & & 21.099 & $<0.001$ \\
Pos & $14.95 \pm 14.45$ & & \\
Neg & $26.63 \pm 22.76$ & 11.313 & 0.001 \\
Microscopy & & & \\
Pos & $16.11 \pm 15.45$ & & \\
Neg & $25.39 \pm 22.41$ & 6.534 & 0.011 \\
varATS qPCR & & & \\
Pos & $19.25 \pm 18.50$ & & \\
Neg & $25.51 \pm 22.54$ & & \\
\hline
\end{tabular}

\section{Conclusions}

This study revealed high cases of asymptomatic malaria in the study population, with varATS detecting additional sub-microscopic infections. The reports suggested that older children were at increased risk of asymptomatic malaria in Bayeku community. A large-scale screening to identify more hotspots of asymptomatic parasite reservoirs in the country is recommended.

\section{Supplementary information}

Supplementary information accompanies this paper at https://doi. org/10.1186/s12936-019-3073-7.

Additional file 1. Calculation of varATS qPCR standards.

Additional file 2. Additional tables.

Additional file 3. varATS/microscopy vs varATS/RDT raw values.

\section{Abbreviations}

ATS: acidic terminal sequence; LASMARTAC: Lagos State Malaria Research, Technical and Advisory Committee; PCR: polymerase chain reaction; RDT: rapid diagnostic test; WBC: white blood cells.

\section{Acknowledgements}

The authors appreciate the co-operation of study participants and the leaders of Bayeku Community. We acknowledge the contributions of all field and laboratory staff.

\section{Authors' contributions}

FAU, KMO and ETI conceived and designed the study. FAU and OA implemented the field study. KMO, FAU, BE, OA and AOS carried out the laboratory studies. KMO and FAU collated and analysed the data. KMO, FAU and ETI drafted the manuscript. AA-N, OAO and GAA edited the manuscript. All authors read and approved the final manuscript.

\section{Funding}

KMO was supported by a DELTAS Africa grant (DEL-15-007: Awandare). The DELTAS Africa Initiative is an independent funding scheme of the African Academy of Sciences (AAS)'s Alliance for Accelerating Excellence in Science in Africa (AESA) and supported by the New Partnership for Africa's Development Planning and Coordinating Agency (NEPAD Agency) with funding from the Wellcome Trust (107,755/Z/15/ZZ: Awandare) and the UK government. The views expressed in this publication are those of the authors and not necessarily those of AAS, NEPAD Agency, Wellcome Trust or the UK government. 


\section{Availability of data and materials}

The datasets supporting the conclusions of this article are included within the article and its additional files.

\section{Ethics approval and consent to participate}

This study was approved by the Institutional Review Board of the Nigerian Institute of Medical Research (IRB/15/289). Individuals were requested to provide a written informed consent or assent (by parents/guardians of children below 16 years) before progressing on any study-related procedure. Confidentiality of the participants and the information provided were assured and maintained throughout the study period. Subjects who tested positive were given age-appropriate course of artemether/lumefantrine (combiart) for free.

\section{Consent for publication}

Not applicable.

\section{Competing interests}

The authors declare that they have no competing interests.

\section{Author details}

${ }^{1}$ Parasitology and Bioinformatics Unit, Department of Zoology, Faculty of Science, University of Lagos, Akoka, Lagos, Nigeria. ${ }^{2}$ Nigerian Institute of Medical Research, Yaba, Lagos, Nigeria. ${ }^{3}$ Medical Research Council at the London School of Hygiene and Tropical Medicine, Fajara, The Gambia. ${ }^{4}$ West African Centre for Cell Biology of Infectious Pathogens, University of Ghana, Legon, Accra, Ghana.

Received: 5 September 2019 Accepted: 13 December 2019 Published online: 19 December 2019

\section{References}

1. World Health Organization. Malaria vaccine: WHO position paper, January 2016 - recommendations. Vaccine. 2018:36:3576-7.

2. MoH FDE. National malaria strategic plan 2014-2020. Addis Ababa: Minister of Health; 2014.

3. Guyant P, Corbel V, Guerin PJ, Lautissier A, Nosten F, Boyer S, et al. Past and new challenges for malaria control and elimination: the role of operational research for innovation in designing interventions. Malar J. 2015;14:279.

4. Schellenberg DM, Aponte JJ, Kahigwa EA, Mshinda H, Tanner M, Menendez C, et al. The incidence of clinical malaria detected by active case detection in children in Ifakara, southern Tanzania. Trans R Soc Trop Med Hyg. 2003;97:647-54.

5. Canier L, Khim N, Kim S, Sluydts V, Heng S, Dourng D, et al. An innovative tool for moving malaria PCR detection of parasite reservoir into the field. Malar J. 2013;12:405.

6. Chen I, Clarke SE, Gosling R, Hamainza B, Killeen G, Magill A, et al. "Asymptomatic"Malaria: a chronic and debilitating infection that should be treated. PLoS Med. 2016;13:e1001942.

7. Galatas B, Bassat Q, Mayor A. Malaria parasites in the asymptomatic: looking for the hay in the haystack. Trends Parasitol. 2016;32:296-308.

8. Lindblade KA, Steinhardt L, Samuels A, Kachur SP, Slutsker L. The silent threat: asymptomatic parasitemia and malaria transmission. Expert Rev Anti Infect Ther. 2013;11:623-39.

9. Bridge J, Hunter BM, Albers E, Cook C, Guarinieri M, Lazarus JV, et al. The Global Fund to Fight AIDS, Tuberculosis and Malaria's investments in harm reduction through the rounds-based funding model (2002-2014). Int J Drug Policy. 2016;27:132-7.

10. Fernando SD, Ihalamulla RL, Wickremasinghe $\mathrm{R}$, de Silva NL, Thilakarathne $\mathrm{JH}$, Wijeyaratne $\mathrm{P}$, et al. Effects of modifying the World Health Organization standard operating procedures for malaria microscopy to improve surveillance in resource poor settings. Malar J. 2014;13:98.

11. Zoghi S, Mehrizi AA, Raeisi A, Haghdoost AA, Turki H, Safari R, et al. Survey for asymptomatic malaria cases in low transmission settings of Iran under elimination programme. Malar J. 2012;11:126.

12. Parker DM, Landier J, von Seidlein L, Dondorp A, White L, Hanboonkunupakarn $B$, et al. Limitations of malaria reactive case detection in an area of low and unstable transmission on the Myanmar-Thailand border. Malar J. 2016;15:571.
13. Tedla M. A focus on improving molecular diagnostic approaches to malaria control and elimination in low transmission settings: review. Parasite Epidemiol Control. 2019;6:e00107.

14. Ndong IC, Okyere D, Enos JY, Amambua-Ngwa A, Merle CSC, Nyarko $A$, et al. Challenges and perceptions of implementing mass testing, treatment and tracking in malaria control: a qualitative study in Pakro sub-district of Ghana. BMC Public Health. 2019;19:695.

15. Kamau E, Tolbert LS, Kortepeter L, Pratt M, Nyakoe N, Muringo L, et al. Development of a highly sensitive genus-specific quantitative reverse transcriptase real-time PCR assay for detection and quantitation of Plasmodium by amplifying RNA and DNA of the 18S rRNA genes. J Clin Microbiol. 2011;49:2946-53.

16. Mosha JF, Sturrock HJ, Greenhouse B, Greenwood B, Sutherland CJ, Gadalla N, et al. Epidemiology of subpatent Plasmodium falciparum infection: implications for detection of hotspots with imperfect diagnostics. Malar J. 2013;12:221.

17. White NJ. The consequences of treating asymptomatic malaria parasitemia. Clin Infect Dis. 2017;64:654-5.

18. Hofmann N, Mwingira F, Shekalaghe S, Robinson LJ, Mueller I, Felger I. Ultra-sensitive detection of Plasmodium falciparum by amplification of multi-copy subtelomeric targets. PLoS Med. 2015;12:e1001788.

19. Mokuolu OA, Ajumobi OO, Ntadom GN, Adedoyin OT, Roberts AA, Agomo CO, et al. Provider and patient perceptions of malaria rapid diagnostic test use in Nigeria: a cross-sectional evaluation. Malar J. 2018;17:200.

20. Mokuolu OA, Ntadom GN, Ajumobi OO, Alero RA, Wammanda RD, Adedoyin OT, et al. Status of the use and compliance with malaria rapid diagnostic tests in formal private health facilities in Nigeria. Malar J. 2016;15:4.

21. Falade CO, Ajayi IO, Nsungwa-Sabiiti J, Siribie M, Diarra A, Serme L, et al. Malaria rapid diagnostic tests and malaria microscopy for guiding malaria treatment of uncomplicated fevers in Nigeria and prereferral cases in 3 African countries. Clin Infect Dis. 2016;63(suppl 5):S290-7.

22. Falade $\mathrm{CO}$, Adesina-Adewole B, Dada-Adegbola HO, Ajayi IO, Akinyemi JO, Ademowo OG, et al. Evaluation of Paracheck-Pf(TM) rapid malaria diagnostic test for the diagnosis of malaria among HIV-positive patients in Ibadan, south-western Nigeria. Pathog Glob Health. 2013;107:69-77.

23. Eludoyin OM, Adelekan IO, Webster R, Eludoyin AO. Air temperature, relative humidity, climate regionalization and thermal comfort of Nigeria. Int J Climatol. 2014;34:2000-18.

24. Aina OO, Agomo CO, Olukosi YA, Okoh HI, Iwalokun BA, Egbuna KN, et al. Malariometric survey of Ibeshe community in Ikorodu, Lagos State: dry season. Malar Res Treat. 2013;2013:487250.

25. Drakeley CJ, Corran PH, Coleman PG, Tongren JE, McDonald SL, Carneiro , et al. Estimating medium- and long-term trends in malaria transmission by using serological markers of malaria exposure. Proc Natl Acad Sci USA. 2005;102:5108-13.

26. Alexander N, Schellenberg D, Ngasala B, Petzold M, Drakeley C, Sutherland $C$. Assessing agreement between malaria slide density readings. Malar J. 2010;9:4.

27. White NJ. The management of severe falciparum malaria. Am J Respir Crit Care Med. 2003;167:673-4.

28. Altman DG. Practical statistics for medical research. London: Chapman and Hall; 1991. p. 406-7.

29. Ladeia-Andrade S, Ferreira MU, de Carvalho ME, Curado I, Coura JR. Age-dependent acquisition of protective immunity to malaria in riverine populations of the Amazon Basin of Brazil. Am J Trop Med Hyg. 2009;80:452-9.

30. Arango EM, Samuel R, Agudelo OM, Carmona-Fonseca J, Maestre A, Yanow SK. Molecular detection of malaria at delivery reveals a high frequency of submicroscopic infections and associated placental damage in pregnant women from northwest Colombia. Am J Trop Med Hyg. 2013;89:178-83.

31. Bousema T, Griffin JT, Sauerwein RW, Smith DL, Churcher TS, Takken W, et al. Hitting hotspots: spatial targeting of malaria for control and elimination. PLoS Med. 2012;9(1):e1001165.

32. O'Meara WP, Bejon P, Mwangi TW, Okiro EA, Peshu N, Snow RW, et al. Effect of a fall in malaria transmission on morbidity and mortality in Kilifi, Kenya. Lancet. 2008;372:1555-62. 
33. Ochola LB, Marsh K, Lowe B, Gal S, Pluschke G, Smith T. Estimation of the sequestered parasite load in severe malaria patients using both host and parasite markers. Parasitology. 2005;131:449-58.

34. Lo E, Zhou G, Oo W, Afrane Y, Githeko A, Yan G. Low parasitemia in submicroscopic infections significantly impacts malaria diagnostic sensitivity in the highlands of Western Kenya. PLOS ONE. 2015;10:e0121763.

35. Zhou Z, Mitchell RM, Kariuki S, Odero C, Otieno P, Otieno K, et al. Assessment of submicroscopic infections and gametocyte carriage of Plasmodium falciparum during peak malaria transmission season in a community-based cross-sectional survey in western Kenya, 2012. Malar J. 2016;15:421.

36. Ouedraogo M, Samadoulougou S, Rouamba T, Hien H, Sawadogo JEM,

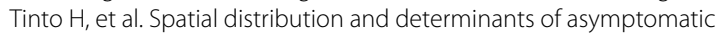
malaria risk among children under 5 years in 24 districts in Burkina Faso. Malar J. 2018;17:460.

37. Kamanga A, Moono P, Stresman G, Mharakurwa S, Shiff C. Rural health centres, communities and malaria case detection in Zambia using mobile telephones: a means to detect potential reservoirs of infection in unstable transmission conditions. Malaria J. 2010;9:96.

38. Ahorlu CK, Koram KA, Seake-Kwawu A, Weiss MG. Two-year evaluation of Intermittent Preventive Treatment for Children (IPTC) combined with timely home treatment for malaria control in Ghana. Malar J. 2011;10:127.
39. Bottius E, Guanzirolli A, Trape JF, Rogier C, Konate L, Druilhe P. Malaria: even more chronic in nature than previously thought; Evidence for subpatent parasitaemia detectable by the polymerase chain reaction. Trans $R$ Soc Trop Med Hyg. 1996;90:15-9.

40. Walldorf JA, Cohee LM, Coalson JE, Bauleni A, Nkanaunena K, KapitoTembo A, et al. School-age children are a reservoir of malaria infection in Malawi. PLoS ONE. 2015;10:e0134061.

41. Douglas NM, John GK, von Seidlein L, Anstey NM, Price RN. Chemotherapeutic strategies for reducing transmission of Plasmodium vivax malaria. Adv Parasitol. 2012;80:271-300.

42. Makanga M. A review of the effects of artemether-lumefantrine on gametocyte carriage and disease transmission. Malar J. 2014;13:291.

43. Oyebola KM, Aina OO, Idowu ET, Olukosi YA, Ajibaye OS, Otubanjo OA, et al. A barcode of multilocus nuclear DNA identifies genetic relatedness in pre- and post-Artemether/Lumefantrine treated Plasmodium falciparum in Nigeria. BMC Infect Dis. 2018;18:392.

\section{Publisher's Note}

Springer Nature remains neutral with regard to jurisdictional claims in published maps and institutional affiliations.
Ready to submit your research? Choose BMC and benefit from:

- fast, convenient online submission

- thorough peer review by experienced researchers in your field

- rapid publication on acceptance

- support for research data, including large and complex data types

- gold Open Access which fosters wider collaboration and increased citations

- maximum visibility for your research: over $100 \mathrm{M}$ website views per year

At BMC, research is always in progress.

Learn more biomedcentral.com/submissions 